\title{
Examination of the 16S-23S rRNA Intergenic Spacer Sequences of 'Candidatus Mycoplasma haemobos' and Mycoplasma haemofelis
}

\author{
Fumina SASAOKA ${ }^{1)}$, Jin SUZUKI ${ }^{1)}$, Masatoshi FUJIHARA ${ }^{1)}$, Yusaku WATANABE ${ }^{1)}$, Kazuya NAGAI $^{2)}$ and \\ Ryô HARASAWA ${ }^{1) *}$ \\ ${ }^{1)}$ Department of Veterinary Microbiology, Faculty of Agriculture, Iwate University, Morioka 020-8550, Japan \\ ${ }^{2}$ Cryobiofrontier Research Center, Faculty of Agriculture, Iwate University, Morioka 020-8550, Japan
}

(Received 20 July 2011/Accepted 3 August 2011/Published online in J-STAGE 12 August 2011)

ABSTRACT. The intergenic spacer region between the 16S and 23S rRNA genes of mycoplasmas has been used for a genetic marker for identification of the species. Here we show the intergenic spacer regions of two hemotropic mycoplasmas, Mycoplasma haemofelis and 'Candidatus Mycoplasma haemobos (synonym: ' $C$. M. haemobovis')' are also useful for classification of this particular group of mycoplasms. The spacer region of $M$. haemofelis and ' $C$. M. haemobos' consisted of 209 and 210 base pairs, respectively, and both lacked the spacer tRNA genes. Phylogenetic analysis suggested a monophyletic relationship among hemoplasmas and M. fastidiosum. A hypothetical secondary structure predicted in the spacer regions tentatively assigned the boxA and boxB motifs peculiar to the members of the genus Mycoplasma. M. haemofelis and ' $C$. M. haemobos' possessed a stem-loop structure in common, despite the presence of a palindromic nucleotide substitution in the stem region.

KEY WORDS: 16S-23S rRNA, haemoplasma, mycoplasma.

doi: 10.1292/jvms.11-0344; J. Vet. Med. Sci. 74(1): 83-87, 2012

Hemoplasmas, hemotropic mycoplasmas, are causative of infectious anemia in animals, but have never been cultured in vitro $[16,17]$. The members of the genus Mycoplasma have only one or two operons for the rRNA gene [1]. The genes encoding for rRNA molecules of the genus Mycoplasma are usually organized in the order of 5'-16S23S-5S-3', in which the individual rRNA genes are separated by internal transcribed spacer (ITS) regions [22], except for Mycoplasma suis [14, 19]. The ITS region between the 16S and 23S rRNA genes of the genus Mycoplasma has been shown to lack spacer tRNA genes so far [15] and to be variable in sequence and length depending on the species [27]. Thus the ITS region has been used as a genetic marker for comparing phylogenetic relationships of genetically closely related species among not only the mycoplasmas [5], but also other bacterial species [3, 12, 13, 25]. Therefore, analyses of ITS regions may provide useful information for defining the genealogical positions of hemoplasmas. In the present study, we examined the ITS sequences of two hemoplasma species, Mycoplasma haemofelis $[16,17]$ and 'Candidatus Mycoplasma haemobos (synonym: ' $C$. M. haemobovis')' [24], both causative of infectious anemia in cats and cattle, respectively.

Heparin or EDTA-anticoagulated blood samples collected from cats in Morioka and cattle in Miyazaki, Japan, were kept at $-20^{\circ} \mathrm{C}$ prior to analysis. Total DNA was extracted from $200 \mu l$ of the anticoagulated whole blood

\footnotetext{
* Correspondence to: Harasawa, R., Department of Veterinary Microbiology, Faculty of Agriculture, Iwate University, Morioka 020-8550, Japan.

e-mail: harasawa-tky@umin.ac.jp

(C)2012 The Japanese Society of Veterinary Science
}

samples by using the QIAamp DNA Blood Mini Kit (QIAGEN, Hilden, Germany) according to the manufacturer's instructions, eluting into $200 \mu l$ of buffer AE, and stored at $-20^{\circ} \mathrm{C}$ until examination in the PCR assay. Two hemoplasma species, $M$. haemofelis and ' $C$. M. haemobos', identified in the present study according to the methods as described previously $[2,18]$, were further subjected to analysis of the ITS region between the $16 \mathrm{~S}$ and $23 \mathrm{~S}$ rRNA genes. No mixed infection was apparent in each animal that these hemoplasmas were detected.

ITS region was amplified from the total DNA extracted from ' $C$. M. haemobos' strain Gandail and M. haemofelis strain Gandai2. PCR amplification of the isolated DNA was carried out at $94^{\circ} \mathrm{C}$ for $30 \mathrm{sec}, 55^{\circ} \mathrm{C}$ for $2 \mathrm{~min}$, and $72^{\circ} \mathrm{C}$ for 2 min for 30 cycles using forward (5'-GTTCCCAGGTCTTGTACACA-3') and reverse (5'-CAGTACTTGTTCACTATCGGTA-3') primers as described previously [4]. The PCR products were fractionated on horizontal, submerged $1.0 \%$ SeaKem ME agarose gels (FMC Bioproducts, Rockland, Me., U.S.A.) in TAE (40 mM Tris, pH8.0, $5 \mathrm{mM}$ sodium acetate, $1 \mathrm{mM}$ disodium ethylenediaminetetracetate) buffer at 50 volts for $60 \mathrm{~min}$. After electrophoresis, the gels were stained in ethidium bromide solution $(0.4 \mu \mathrm{g} / \mathrm{m} l)$ for $15 \mathrm{~min}$ and visualized under UV transilluminator. ITS regions of only $M$. haemofelis and ' $C$. M. haemobos' were successfully amplified by this PCR. DNA in a clearly visible band was extracted by using NucleoSpin Extract II kit (Macherey-Nagel, Düren, Germany) and was subjected to direct sequencing in a 3500 Genetic Analyzer (Applied Biosystems, Foster City, Calif., U.S.A.). The GenBank/EMBL/ DDBJ accession numbers for the 16S-23S rRNA intergenic spacer sequence of ' $C$. M. haemobos' strain Gandail and $M$. haemofelis strain Gandai2 are AB638407 and AB638408, 
respectively. Reason for unsuccessful amplification of ITS of other hemoplasma species by this PCR remains unidentified. Mismatches in PCR primers were most likely in these cases.

The ITS region between the $16 \mathrm{~S}$ and $23 \mathrm{~S}$ rRNA genes of the genus Mycoplasma is well conserved within a species and used for a genetic marker for identification and classification of mycoplasmas [5]. ITS regions of M. haemofelis and ' $C$. M. haemobos' were consisting of 209 and 210 base pairs, respectively. The nucleotide sequences of the ITS in these 2 species showed moderate similarity with that of $M$. haemomuris previously determined [8], and shared a consensus motifs called boxA and boxB in common (Fig. 1). The boxA, originally found at upstream regions of the nut site of the lambda phage genome, is considered to be a cisacting element for the Escherichia coli NusA protein, a transcription control factor [20]. The conserved nature of the boxA sequence among these different species may implicate an important role in survival mechanisms, though the exact function of this motif in the ITS remains unknown [11]. The boxB sequence previously reported in mycoplasmas [5] was also assigned about ten nucleotides upstream of the boxA sequence of both the hemoplasma species. Presence of these particular motifs suggests that ITS might act as a controlling element for transcription of the rRNA operon in hemoplasmas. No spacer tRNA gene was identified within the ITS of $M$. haemofelis and ' $C$. M. haemobos', and this is a common feature in line with the other species of the genus Mycoplasma [27]. Transposase gene has been demonstrated in ITS of $M$. imitans [10], but such feature was not the case in these two hemoplasma species.

The nucleotide sequences of ITS regions of both the hemoplasmas were compared with authentic mycoplasma species in phylogenetic analysis. In the present study, we explored the genealogical relatedness among 20 mycoplasma species including not only ureaplasmas but also three hemoplasma species, M. haemomuris, M. haemofelis, and ' $C$. M. haemobos'. The comprehensive phylogenetic tree suggested the 20 mycoplasma sequences were divided into three clusters consisting of Hominis, Pneumoniae and Fastidiosum groups (Fig. 2). Hemoplasmas formed a monophyletic clade in the Fastidiosum group in the present study, allowing more precise assignment of hemoplasmas as compared with phylogenetic analysis based on the 16S rRNA sequences $[16,24]$. Although the Hominis and Pneumoniae groups in mycoplasmas have already been established in the phylogenetic analyses based on the 16S rRNA gene as well as on the RNase P RNA gene [21], we showed a monophyletic relationship among hemoplasmas and $M$. fastidiosum by phylogenetically analyzing ITS regions. Our findings support that given hemoplasmas are members of the class Mollicutes.

The secondary structures of the ITS were predicted according to the algorithm of Zuker and Stiegler [28]. Five

\section{M haemobos \\ $M$ haemofelis \\ $M$ haemomuris \\ C M haemobos \\ $M$ haemofelis \\ $M$ haemomuris}

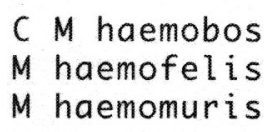

$C$ M haemobos
$M$ haemofelis
$M$ haemomuris

$C$ M haemobos
$M$ haemofelis
$M$ haemomuris

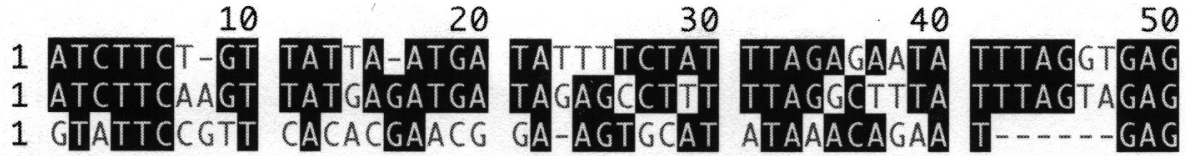

60

70

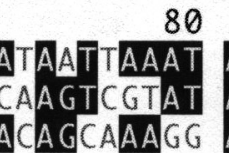

80

51 GTTTTACTTG

51 GTTGTAACT

GACACCCGT
GA-ATAAAT
AATGATGG

AGTTAGATT

90

100

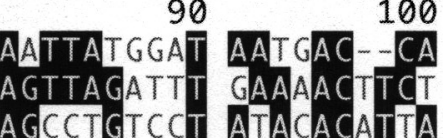

110
101 AGGCGGATGA

101 AGGCGGATGA

101 AGGCGGATGG

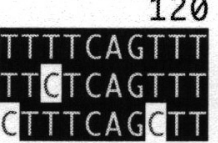

140

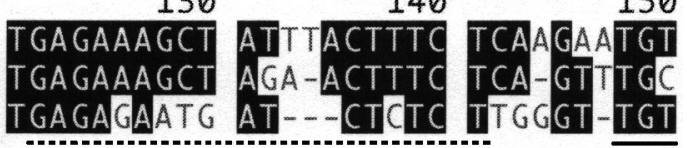

160

151 TTTTTGAAAT

151 TTTTTGAAA

151 TTTTTGAAAA

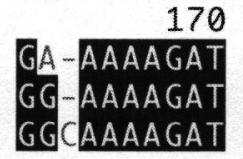

170

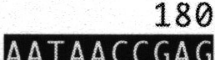

AATAACCGAC

AATAACCGAG

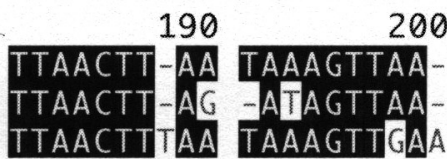

Fig. 1. Nucleotide sequence alignment of ITS from the three hemoplasma species, M. haemofelis, 'C. M. haemobos' and M. haemomuris. The nucleotide sequence of $M$. haemomuris was obtained from the previous report [8]. Nucleotide sequence numbers are given from a consensus sequence. Homologous nucleotides are shown as inverted characters. Dashes indicate nucleotide gaps between adjacent nucleotides introduced for the alignment. BoxA is underlined, and boxB is shown by a dotted line. 


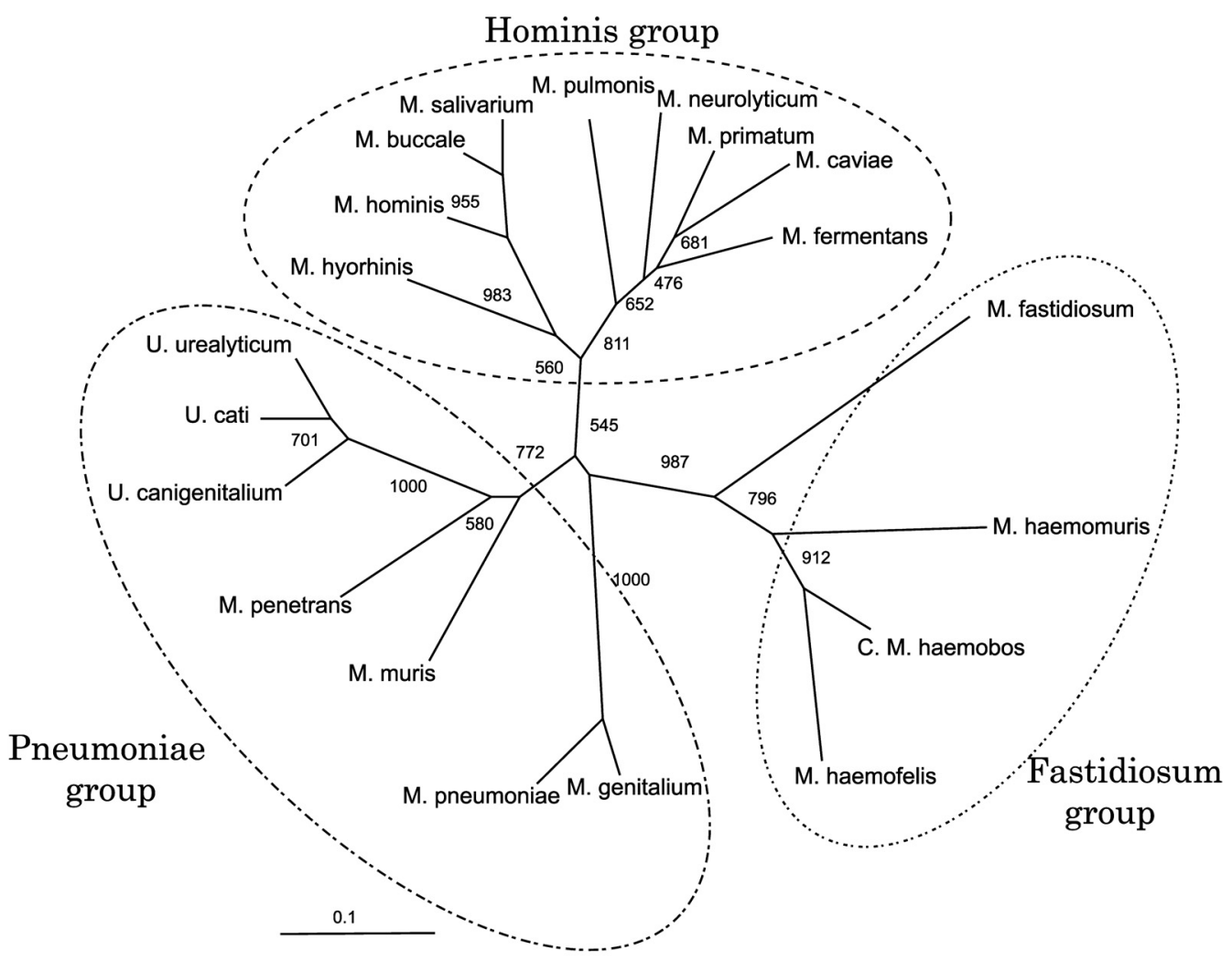

Fig. 2. Unrooted phylogenetic tree based on the ITS comparison, suggesting a monophyletic relationship among hemoplasmas and M. fastidiosum. Following nucleotide sequences were obtained from the DNA databases and accession number is given in parenthesis. They are M. salivarium PG20 (X58558), M. pulmonis m53 (X58554), M. neurolyticum Sabin Type A (X58552), M. buccale CH20247 (D89504), M. primatum HRC292 (D89509), M. caviae G122 (D89505), M. hominis PG21 (X58559), M. fermentans PG18 (X58553), M. hyorhinis BTS-7 (X58555), M. ppenetrans GTU54 (D89508), M. muris RIII4 (D89507), M. pneumoniae Mac (D14528), M. genitalium G37 (D14526), M. fastidiosum ATCC33229 (AY781782), Ureaplasma urealyticum T960 (X58561), U. cati F2 (D636859, U. canigenitalium D6P-C (D63684), M. haemomuris Shizuoka (AB080799), M. haemofelis Gandai2 (AB638408), and ' $C$. M. haemobos' Gandail (AB638407). Scale bar indicates the estimated evolutionary distance that was computed with CLUSTAL W [26] using neighbor-joining method [23]. Numbers in the relevant branches refer to the values of boot-strap probability of 1,000 replications.

stem-loop domains were allocated in ITS of M. haemofelis and ' $C$. M. haemobos' (Fig. 3). The boxA was assigned on the stem portion of domain IV, and this was common to the structure of ' $C$. M. haemomuris' [8]. No identical architecture was evident between these two species. Domain III was seen in both the species in common, despite a single nucleotide substitution that was capable to form a stable secondary structure to minimize free energy, by G-T wobble as well as canonical Watson-Crick base pairings at stem region. Secondary structures in ITS region have sometime provided a key character to distinguish closely related species among mycoplasmas $[6,7,9]$.

Here we demonstrated that ITS regions of hemoplasmas posses a feature of the genus Mycoplasma, and hemoplasmas form a monophyletic relationship with $M$. fastidioum in phylogenetic analysis. A common stem-loop structure was identified in $M$. haemofelis and ' $C$. M. haemobos', though its significance remained unknown.

\section{REFERENCES}

1. Amikam, D., Glaser, G. and Razin, S. 1984. Mycoplasmas (Mollicutes) have a low number of rRNA genes. J. Bacteriol. 158: $376-378$

2. Fujihara, M., Watanabe, M., Yamada, T. and Harasawa, R. 2007. Occurrence of 'Candidatus Mycoplasma turicensis' infection in domestic cats in Japan. J. Vet. Med. Sci. 69: 10611063.

3. Graham, T. A., Golsteyn-Thomas, E. J., Thomas, J. E. and Gannon, V. P. J. 1997. Inter- and intraspecies comparison of the 16S-23S rRNA operon intergenic spacer regions of six Listeria spp. Int. J. Syst. Bacteriol. 47: 863-869.

4. Harasawa, R. 1996. PCR: application of nested PCR to detection of mycoplasmas. pp.75-79. In: Molecular and Diagnostic Procedures in Mycoplasmology, vol. 2 (Razin, S. and Tully, J.G. eds.), Academic Press, New York.

5. Harasawa, R. 1999. Genetic relationships among mycoplasmas based on the 16S-23S rRNA spacer sequence. Microbiol. Immunol. 43: 127-132. 

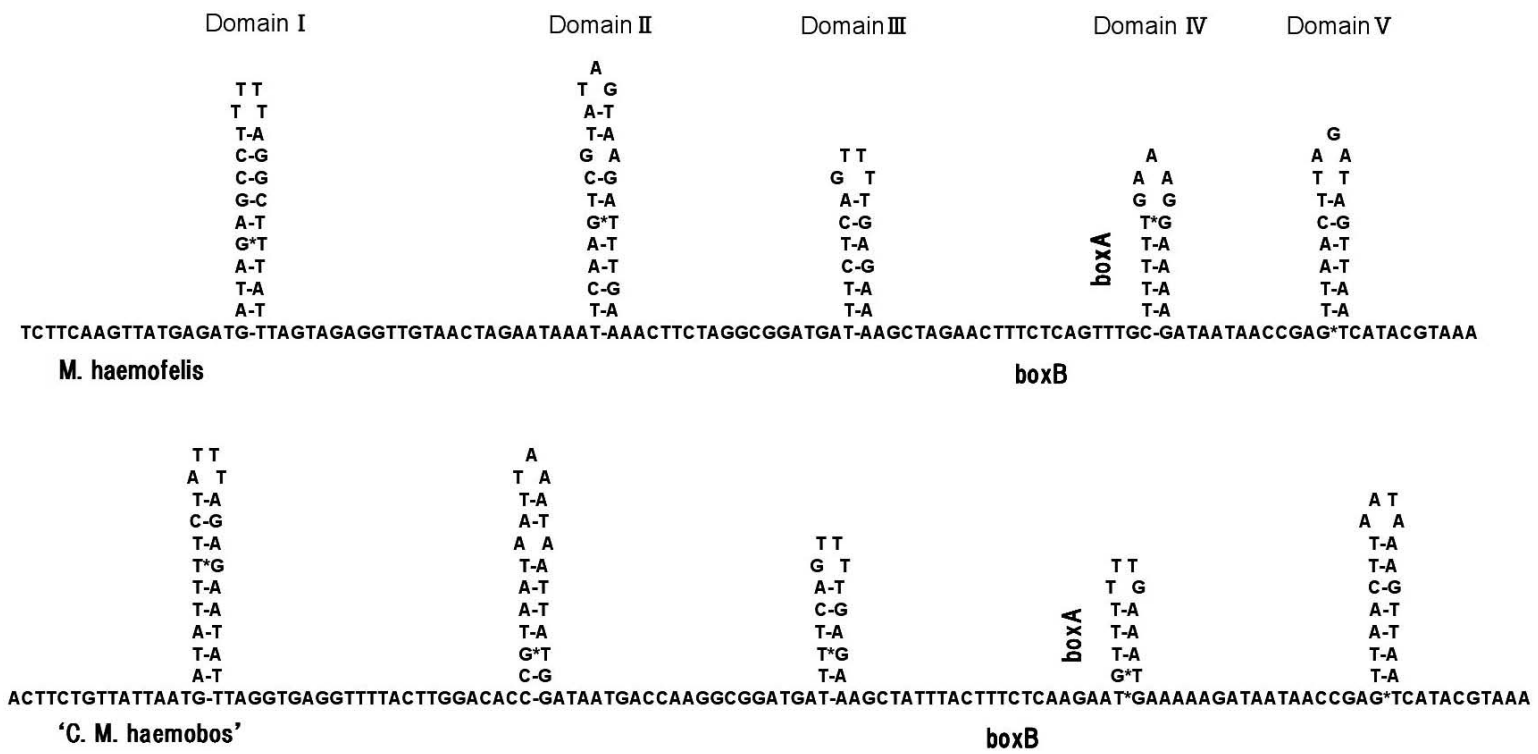

Fig. 3. Hypothetical secondary structures for the ITS of $M$. haemofelis (top) and ' $C$. M. haemobos' (bottom). Canonical WatsonCrick base-pairing is hyphened, and a wobble base-pairing tolerated in the secondary structure is shown by an asterisk. The boxA was a part of the stem region of domain IV, and boxB was located between domains III and IV.

6. Harasawa, R., Hotzel, H. and Sachse, K. 2000. Comparison of the 16S-23S rRNA intergenic spacer regions among strains of the Mycoplasma mycoides cluster, and reassessment of the taxonomic position of Mycoplasma sp. bovine group 7. Int. J. Syst. Evol. Microbiol. 50: 1325-1329.

7. Harasawa, R. and Kanamoto, Y. 1999. Differentiation of two biovars of Ureaplasma urealyticum based on the 16S-23S rRNA intergenic spacer region. J. Clin. Microbiol. 37: 41354138.

8. Harasawa, R., Kawahara, M. and Rikihisa, Y. 2002. Characteristics of the 16S-23S rRNA intergenic spacer region of Mycoplasma haemomuris, previously classified as 'Haemobartonella muris'. J. Vet. Med. Sci. 64: 1161-1164.

9. Harasawa, R., Lefkowitz, E.J., Glass, J.I. and Cassell, G.H. 1996. Phylogenetic analysis of the 16S-23S rRNA intergenic spacer region of the genus Ureaplasma. J. Vet. Med. Sci. 58: 191-195.

10. Harasawa, R., Pitcher, D.G., Ramirez, A.S. and Bradbury, J.M. 2004. A putative transposase gene in the $16 \mathrm{~S}-23 \mathrm{~S}$ rRNA intergenic spacer region of Mycoplasma imitans. Microbiology 150: 1023-1029.

11. Harasawa, R., Uemori, T., Asada, K., Kato, I. and Shiragami, N. 1992. 'boxA'-like sequence between the $16 \mathrm{~S} / 23 \mathrm{~S}$ spacer in the rRNA operon. FEBS Lett. 297: 209-211.

12. Jagoueix, S., Bove, J. M. and Garnier, M. 1997. Comparison of the $16 \mathrm{~S} / 23 \mathrm{~S}$ ribosomal intergenic regions of 'Candidatus Liberobacter asiaticum' and 'Candidatus Liberobacter africanum', the two species associated with citrus huang-longbing (greening) disease. Int. J. Syst. Bacteriol. 47: 224-227.

13. Leblond-Bourget, N., Philippe, H., Mangin, I. and Decaris, B. 1996. 16S rRNA and $16 \mathrm{~S}$ to $23 \mathrm{~S}$ internal transcribed spacer sequence analyses reveal inter- and intraspecific Bifidobacterium phylogeny. Int. J. Syst. Bacteriol. 46: 102-111.

14. Messick, J.B., Santos, A.P. and Guimaraes, A.M. 2011. Complete genome sequences of two hemotropic mycoplasmas, Mycoplasma haemofelis strain Ohio2 and Mycoplasma suis strain Illinois. J. Bacteriol. 193: 2068-2069.

15. Nakagawa, T., Uemori, T., Asada, K., Kato, I. and Harasawa, R. 1992. Acholeplasma laidlawii has tRNA genes in the 16S23S spacer of the rRNA operon. J. Bacteriol. 174: 8163-8165.

16. Neimark, H., Johansson, K.-E., Rikihisa, Y. and Tully, J.G. 2001. Proposal to transfer some members of the genera Haemobartonella and Eperythrozoon to the genus Mycoplasma with descriptions of 'Candidatus Mycoplasma haemofelis', 'Candidatus Mycoplasma haemomuris', 'Candidatus Mycoplasma haemosuis' and 'Candidatus Mycoplasma wenyonii'. Int. J. Syst. Evol. Microbiol. 51: 891-899.

17. Neimark, H., Johansson, K.-E., Rikihisa, Y. and Tully, J.G. 2002. Revision of haemotrophic Mycoplasma species names. Int. J. Syst. Evol. Microbiol. 52: 683.

18. Nishizawa, I., Sato, M., Fujihara, M., Sato, S. and Harasawa, R. 2010. Differential detection of hemotropic Mycoplasma species in cattle by melting curve analysis of PCR products. $J$. Vet. Med. Sci. 72: 77-79. (Erratum, J. Vet. Med. Sci. 72: 1704.)

19. Oehlerking, J., Kube, M., Felder, K. M., Matter, D., Wittenbrink, M. M., Schwarzenbach, S., Kramer, M. M., Hoelzle, K. and Hoelzle, L. E. 2011. Complete genome sequence of the hemotrophic Mycoplasma suis strain KI3806. J. Bacteriol. 193: 2369-2370.

20. Olson, E.R., Tomich, C.-S. and Friedman, D.I. 1987. The nusA recognition site. J. Mol. Biol. 180: 1053-1063.

21. Peters, I.R., Helps, C.R., McAuliffe, L., Neimark, H., Lappin, M.R., Gruffydd-Jones, T.J., Day, M.J., Hoelzle, L. E., Willi, B., Meli, M., Hofmann-Lehmann, R. and Tasker, S. 2008. RNase P RNA gene $(r n p B)$ phylogeny of hemoplasmas and other Mycoplasma species. J. Clin. Microbiol. 46: 1873-1877.

22. Razin, S. 1985. Molecular biology and genetics of mycoplasmas (Mollicutes). Microbiol. Rev. 49: 419-455.

23. Saitou, N. and Nei, M. 1987. The neighbor-joining method: a new method for reconstructing phylogenetic trees. Mol. Biol. Evol. 4: 406-425.

24. Tagawa, M., Matsumoto, K. and Inokuma, H. 2008. Molecular 
detection of Mycoplasma wenyonii and 'Candidatus Mycoplasma haemobos' in cattle in Hokkaido, Japan. Vet. Microbiol. 132: 177-180.

25. Thain, T., Ward-Rainey, N., Kroppenstedt, R. M., Stackebrandt, E. and Rainey, F.A. 1977. Discrimination of Streptomyces albidoflavus strains based on the size and number of 16S23S ribosomal DNA intergenic spacers. Int. J. Syst. Bacteriol. 47: 202-206.

26. Thompson, J.D., Higgins, D.G. and Gibson, T.J. 1994. CLUSTAL W: improving the sensitivity of progressive multi- ple sequence alignment through sequence weighting, positionspecific gap penalties and weight matrix choice. Nucleic Acids Res. 22: 4673-4680.

27. Uemori, T., Asada, K., Kato, I. and Harasawa, R. 1992. Amplification of the 16S-23S spacer region in rRNA operons of mycoplasmas by the polymerase chain reaction. Syst. Appl. Microbiol. 15: 181-186.

28. Zuker, M. and Stiegler, P. 1981. Optimal computer folding of large RNA sequences using thermodynamics and auxiliary. Nucleic Acids Res. 9: 133-148. 